\title{
Exploring advanced technology gas turbine engine design and performance for the Large Civil Tiltrotor (LCTR)
}

\author{
Christopher A. Snyder ${ }^{*}$ \\ NASA Glenn Research Center, Cleveland, OH, 44135
}

\begin{abstract}
A Large Civil Tiltrotor (LCTR) conceptual design was developed as part of the NASA Heavy Lift Rotorcraft Systems Investigation in order to establish a consistent basis for evaluating the benefits of advanced technology for large tiltrotors. The concept has since evolved into the second-generation LCTR2, designed to carry 90 passengers for 1,000 nautical miles at 300 knots, with vertical takeoff and landing capability. This paper explores gas turbine component performance and cycle parameters to quantify performance gains possible for additional improvements in component and material performance beyond those identified in previous LCTR2 propulsion studies and to identify additional research areas. The vehicle-level characteristics from this advanced technology generation 2 propulsion architecture will help set performance levels as additional propulsion and power systems are conceived to meet ever-increasing requirements for mobility and comfort, while reducing energy use, cost, noise and emissions. The Large Civil Tiltrotor vehicle and mission will be discussed as a starting point for this effort. A few, relevant engine and component technology studies, including previous LCTR2 engine study results will be summarized to help orient the reader on gas turbine engine architecture, performance and limitations. Study assumptions and methodology used to explore engine design and performance, as well as assess vehicle sizing and mission performance will then be discussed. Individual performance for present and advanced engines, as well as engine performance effects on overall vehicle size and mission fuel usage, will be given. All results will be summarized to facilitate understanding the importance and interaction of various component and system performance on overall vehicle characteristics.
\end{abstract}

\section{Nomenclature}

$\begin{array}{ll}\text { ATG1 } & \text { Advanced Technology Generation 1 (Figures 12-16) } \\ \text { ATG2 } & \text { Advanced Technology Generation } 2 \text { (Figures 12-16) } \\ \text { FAP } & \text { Fundamental Aeronautics Program } \\ \text { FG-VSPT } & \text { fixed-geometry variable-speed power turbine } \\ \text { HPC } & =\text { high-pressure compressor } \\ \text { HPT } & =\text { high-pressure turbine } \\ \text { ISA } & =\text { International Standard Atmosphere } \\ \text { lbm } & =\text { pounds mass } \\ \text { LTO } & =\text { Landing / Takeoff } \\ \text { LCTR } & =\text { Large Civil Tiltrotor } \\ \text { LCTR2 } & =\text { Large Civil Tiltrotor - iteration } 2 \\ \text { LPC } & =\text { low-pressure compressor } \\ \text { LPT } & =\text { low-pressure turbine } \\ \text { MCP } & =\text { maximum continuous power } \\ \text { NOx } & =\text { oxides of nitrogen } \\ \text { NPSS } & =\text { Numerical Propulsion System Simulation } \\ \text { OEI } & =\text { One-engine inoperative } \\ \text { OGE } & =\text { Out of Ground Effect } \\ \text { OPR } & =\text { overall pressure ratio }\end{array}$

\footnotetext{
* Aerospace Engineer, Propulsion Systems Analysis Branch, MS 5-11.
} 


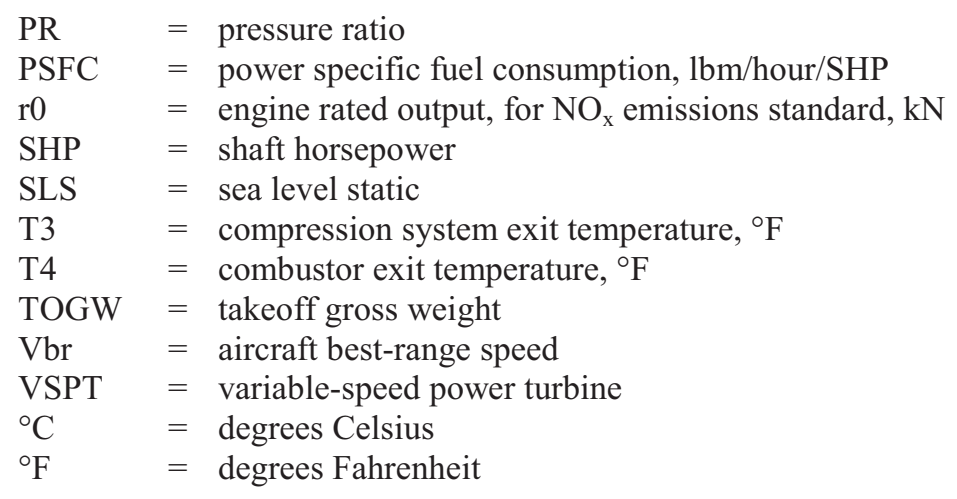

\section{Introduction}

THE Large Civil Tiltrotor (LCTR) conceptual design was developed as part of the NASA Heavy Lift Rotorcraft Systems Investigation ${ }^{1}$. Results from this effort suggested the tiltrotor had some potential performance benefits versus other studied configurations for the chosen, reference mission: carry 120 passengers for 1,200 nautical miles, cruising at 350 knots and 30,000 ft., with vertical takeoff and landing capability. Mission requirements (payload, range, etc.) evolved into the second-generation LCTR2, described in detail in References 2 and 3 and shown in Fig. 1. The LCTR2 design goal is to carry 90 passengers for 1,000 nautical miles at 300 knots, with vertical takeoff and landing capability. It is powered by four 7,500 shaft horsepower (SHP) turboshaft engines (two engines in each rotating propulsion nacelle). Another design feature included a rotor tip speed of $650 \mathrm{ft} . / \mathrm{s}$ in hover and $350 \mathrm{ft} / \mathrm{s}$ during cruise, enabled by a two-speed gearbox. This range of rotor tip speeds was needed to achieve the high level of performance and efficiency at two very different flight conditions as well as reduce noise. The overall purpose of the design effort is to develop a consistent basis for evaluating the benefits of advanced technology for large tiltrotors. This paper explores gas turbine component performance and cycle parameters to quantify additional performance gains possible for additional improvements in component performance beyond that identified in previous LCTR2 propulsion studies and identify additional research areas required to achieve these estimated component performance levels.

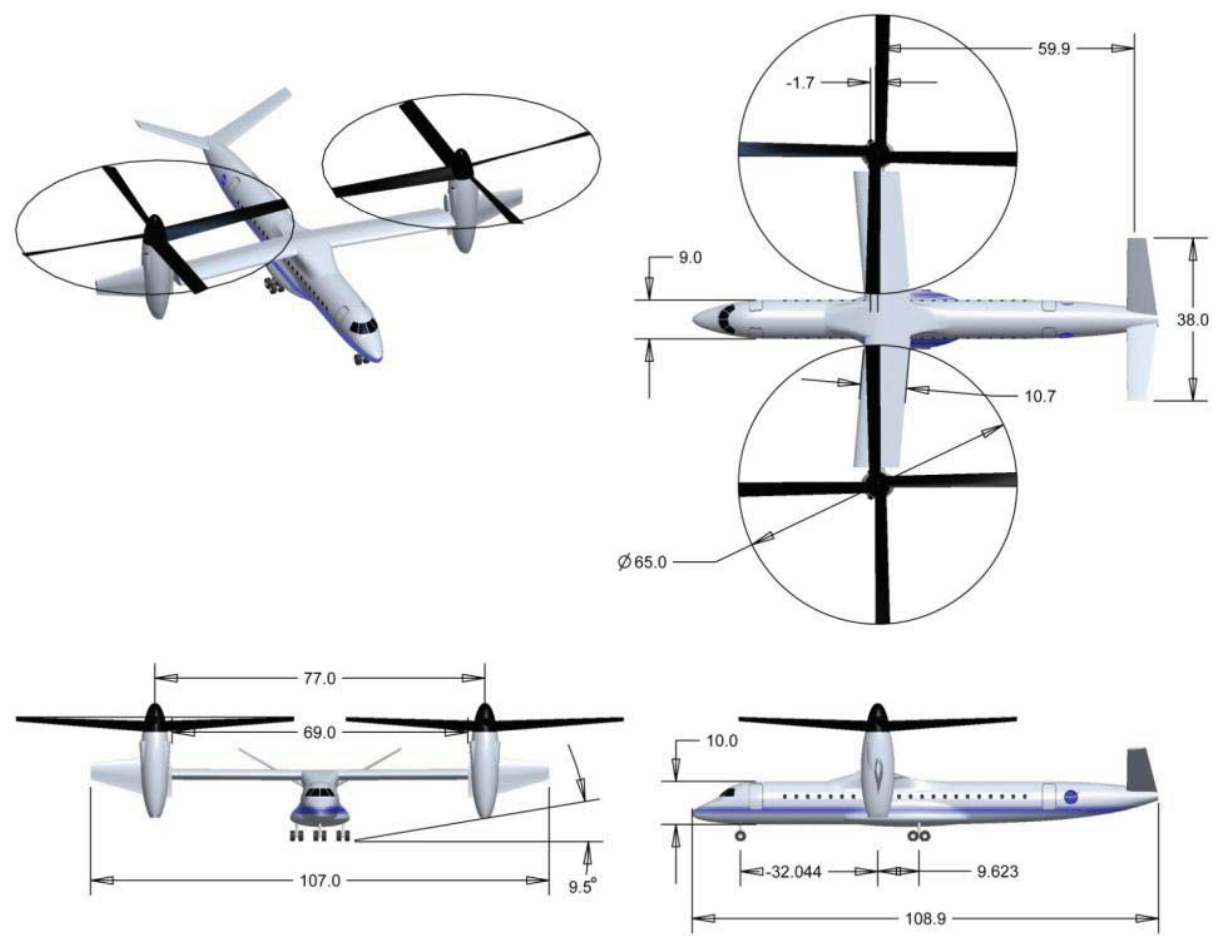

Figure 1. The NASA Large Civil Tiltrotor, LCTR2 baseline version (dimensions in feet). 
The original Heavy-Lift study was focused on determining the best rotorcraft configuration to achieve mission requirements. Rotor speed at hover and cruise were defined from expert opinion; to be refined as study efforts progressed and analysis methodology and tools advanced. To simulate advanced propulsion characteristics, current engine characteristics were used, with adjustments for expected improvements in power-to-weight and fuel efficiency. Multi-speed gearboxes were assumed to achieve the wide variation in rotor speed for the reference mission. Once the rotorcraft configuration was chosen, subsequent efforts refined vehicle requirements and delved into major subsystem definition, performance modeling and requirements.

Development of rotor performance estimates for system studies indicated the potential for a synergistic interaction between rotor and wing / vehicle aerodynamics ${ }^{2-4}$, but is highly dependent on rotor cruise rpm value. This highlighted the interdependence of rotor and the engine / gearbox design. High rotor rpm reduces drive-train torque, hence weight, but the associated high tip speed reduces rotor efficiency in cruise. With a single-speed (fixedratio) gearbox, rpm also affects engine efficiency and power capability. Both rotor and engine performance are further affected by the radically different requirements for efficient cruise and emergency conditions (one-engine inoperative, OEI) in hover. Therefore, there is a multidimensional tradeoff between rotor efficiency, engine efficiency, gearbox weight, and engine weight, all varying with the mission requirements. Understanding and modeling these interactions are important to determine the importance of different technologies.

Engine system studies and detailed engine component research were conducted ${ }^{5-12}$ to understand engine component performance and define a potential, advanced turboshaft engine design. These studies indicated that significant reductions in vehicle and engine size and mission fuel could be achieved using advanced propulsion technology. For purposes of this study, the advanced technology LCTR2 baseline engine developed during those studies will be considered the advanced technology generation 1 engine. But further gains in component and overall engine performance are possible. Therefore the purpose of this paper is to identify and estimate the further improvements in component performance achievable, develop advanced technology generation 2 engine design characteristics and performance, quantify the potential benefits using this new engine design for the LCTR2 vehicle sizing and mission, and discuss the particular research and technology focus areas for these improvements to be achieved. This work will start by reviewing previous propulsion concepts and study results from LCTR2. To define component performance limits for the advanced technology generation 2 gas turbine engine, previous studies focused on improving engine efficiency will be integrated with more modern efforts. The methodology and analysis methods for engine and vehicle sizing and mission analysis will be discussed. This will include the study assumptions and rationale for critical engine and vehicle design parameters. Results will be reported starting with gas turbine engine performance; how the inclusion of technology changes engine size, weight and efficiency from current to the advanced technology generation 1 and 2 engine cycles. Vehicle sizing and mission analysis will be presented and discussed next, emphasizing reductions in mission fuel and engine size and power.

\section{Propulsion Concepts}

\section{A. Previous LCTR Propulsion Studies}

The Heavy Lift study defined targets for overall engine power-to-weight and fuel efficiency [as defined by power-specific fuel consumption (PSFC)]. Efforts to define the engine architecture ${ }^{7-9}$ evolved from a single-spool to two-spool gas generator core, which supplies high pressure and temperature gas to a power turbine to drive the LCTR2 rotors. The flow path representation of that configuration is shown in Figure 2 and was used to explore engine operation and requirements over the baseline mission, as well as varying mission and OEI requirements to determine the effect on engine and vehicle sizing. Some results from those efforts will be mentioned next.

Reference 9 showed that for a two-spool gas generator core engine, the high-pressure core operates at almost constant, corrected conditions over the entire flight profile, engine power reductions are achieved through relatively small reductions in the low-spool rpm. References 9 and 11 looked at OEI requirements and how they affected vehicle design. OEI is a critical engine sizing condition, requiring a short duration (2.5 minute) additional emergency power capability 5\% above engine maximum rated power to enable safe landing capability in the event of loss of one engine anytime during flight. The most stringent OEI sizing condition is fully-loaded, high / hot (5k ISA $+20^{\circ} \mathrm{C}$ ) vertical takeoff, at zero velocity. Assuming a nominal 20 knots forward speed during OEI reduces engine power requirements, reducing vehicle and engine size. Sizing for OEI also results in the engines being significantly oversized for typical missions, suggesting that sufficient performance margins are available which should result in reduced engine maintenance requirements. Other analyses ${ }^{11}$ suggest that if cruise altitude could be increased above the nominal 28,000 foot value (which depends upon LCTR integration in the airspace, thrust margin requirements, and engine thrust lapse) some reduction in mission fuel may be possible. 


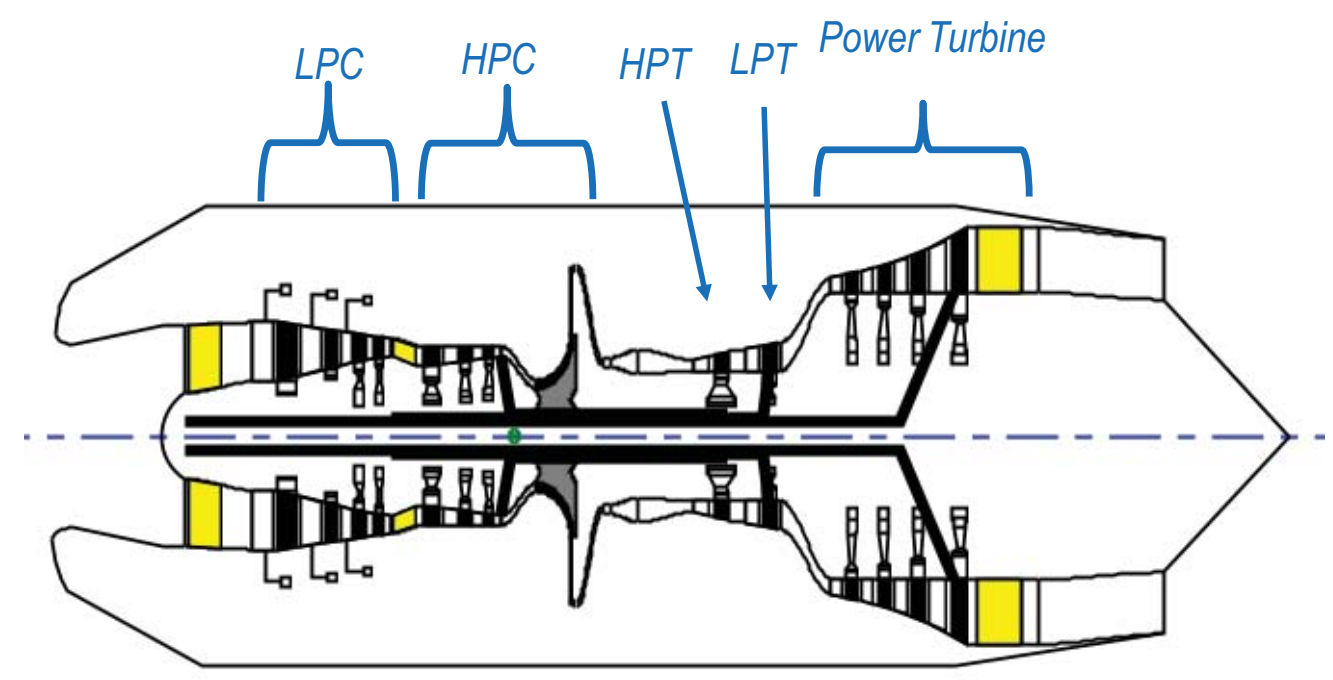

Figure 2. Flow path representation of LCTR2 baseline engine.

To obtain the significant, almost $50 \%$ reduction in rotor speed from hover to cruise, various multi-speed gearbox design concepts were explored to identify potential shifting strategies, develop requirements, and distinguish specific research needs ${ }^{13-15}$. Choosing a multi-speed gearbox / drive system allows the advanced turboshaft engines to operate near their optimum rotational speed and efficiency over most of the mission. As an alternative approach, an earlier study ${ }^{16}$ explored various power turbine configurations to meet the wide range of rotor speeds with high overall efficiency, using a single, fixed-speed gearbox and drive system. Reference 17 is an overview of various NASA research efforts exploring variable-speed power turbine (VSPT) technology to maintain engine power turbine efficiency at the reduced rotor cruise speed with a single-speed drive system.

References 11 and 12 detail assumptions and results from achieving the reduction in cruise rotor tip speed using VSPT technology with a single-speed gearbox versus a more-traditional power turbine design with a multi-speed gearbox. It is interesting to note that for the optimum combinations of VSPT with single-speed gearbox and the more traditional power turbine design with a multi-speed gearbox were very similar in overall vehicle takeoff gross weight (TOGW). For those optimum solutions, NASA reported that the VSPT solution resulted in minimum TOGW, but only $0.5 \%$ lighter than the multi-speed gearbox solution, essentially equivalent propulsion and drive system weights and $2.6 \%$ less fuel burn. Contracted efforts ${ }^{5,10}$ reported that the traditional power turbine design with multi-speed was the minimum TOGW solution, $0.5 \%$ lighter than the VSPT / single-speed gearbox combination. The traditional power turbine design with multi-speed gearbox increased propulsion and drive system weight by almost 5\%, but resulted in 5.2\% lower fuel burn. These results are strongly dependent on the technology assumptions for efficiency and weight for the VSPT and gearbox systems.

\section{B. Previous Engine Component Studies}

Gas turbine engines continue to evolve, improving power-to-weight, fuel efficiency, emissions, life, etc. Reviewing previous research efforts and development trends can be illustrative of limits encountered and overcome, as well as recognizing areas that need to be revisited as modeling, manufacturing, and material technologies improve. Engine design parameters may be interrelated: for instance, increasing burner temperature can increase engine power for a given airflow size, but may require more advanced materials (increasing cost and possibly weight) and increase harmful emissions. There are additional constraints for smaller engines, where turbomachinery blade sizes may already be small in the high pressure sections of the engine. Small blade sizes increase the losses from low Reynolds number, surface roughness, tip gap clearances and other effects and are often at the limit for material capabilities and manufacturability. All axial turbomachinery designs are often preferred, but at some point, an all axial compression system is not a viable design choice and the compression system choice becomes a centrifugal or axial-centrifugal design. Additional background and discussion on various aspects of compression system research related to this effort can be found in Reference 6 .

Work under small engine technology programs ${ }^{18-19}$ looked at various engine cycles, while small engine component technology (SECT) ${ }^{20}$ was more focused on gas turbine-specific technologies. New materials and other 
improvements were identified to reduce weight and fuel usage, and enhance temperature capabilities, reducing cooling requirements and losses. Specific technologies for gas turbines were explored for turbomachinery design and manufacturing to also identify and reduce losses and improve efficiency. Current and advanced technology polytropic efficiency goals are shown in Figure 3 (Figure 14 from Ref. 19).

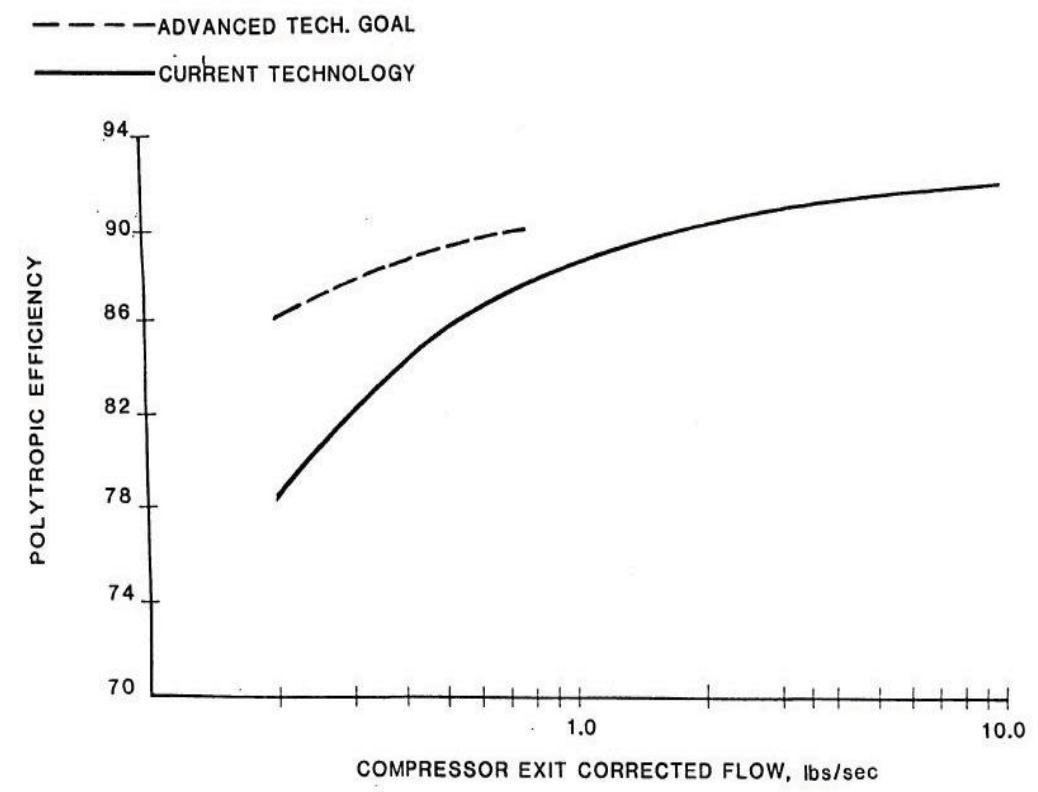

Figure 3. Compressor efficiency trends (from Ref. 19).

Another option considered was using recuperators (heat exchangers) to capture and reuse exhaust waste heat. Recuperators can add significantly to engine size; Figure 4 (Figure 21 from Ref. 20) illustrates an example of increased engine size for adding a recuperator to a turbofan engine. Recovering exhaust waste heat can double fuel efficiency for very small engines sizes which are often limited by low turbomachinery efficiencies and overall pressure ratios (OPRs). Heat exchangers can also be used in turbofan cycles to cool the compression stream, reducing compressor work, reducing compression exit temperature (T3), enabling the use of lower-temperaturecapability compressor materials and reduce oxides of nitrogen $\left(\mathrm{NO}_{\mathrm{x}}\right)$. This heat energy can be added to the turbofan bypass stream to potentially gain thrust from the Meredith effect ${ }^{21}$. However, for an advanced, high OPR turboshaft engine, exhaust temperature is cooler than T3; there is no cold stream available (except before or early in the compression process) to dump waste heat. In addition, any heat exchanger pressure loss is detrimental to engine performance. Therefore, exploring recuperation or heat exchangers will be deferred to potential future studies.

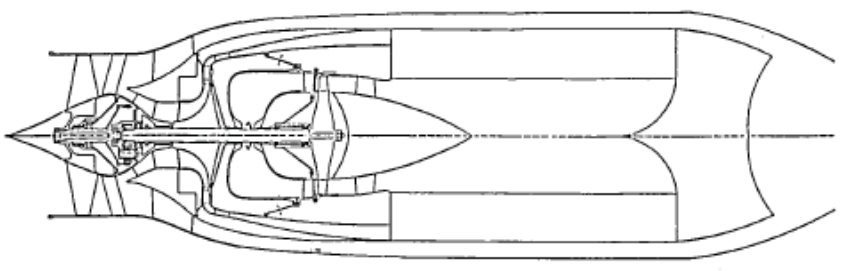

RECUPERATED TURBOFAN

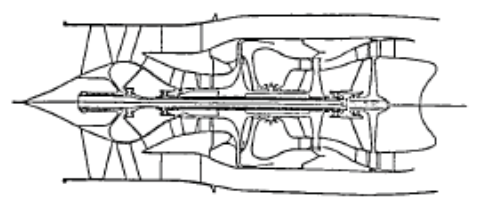

ADVANCED TURBOFAN

Figure 4. Engine configuration with and without recuperator (from Ref. 19).

American Institute of Aeronautics and Astronautics 
Recently, significant research has occurred under the support of NASA's Fundamental Aeronautics Program (FAP). The FAP Rotary Wing Project reported work on progress, achievements, and notional compressor polytropic efficiency characteristics versus flow and technology level for present and next-generation engines, as shown in Figure 5 (from Ref. 6). Progress in materials, aerodynamics and manufacturing is enabling significant improvements in power-to-weight and fuel efficiency for future gas turbine engines. Further efforts are underway to estimate what further gains in turbomachinery aerodynamic performance are possible. An example is work supported by the FAP Fixed Wing project at MIT by Hall ${ }^{22}$ and DiOrio ${ }^{23}$. Hall focused on estimating an upper bound for achievable efficiency, trying to minimize and quantify losses that are inherent in turbomachinery, without constraints for an actual engine design. Hall reported maximum compressor stage efficiencies of $95.5 \%$ and an even higher potential turbine efficiency of $97.2 \%$. DiOrio's work focused on the potential high-bypass turbofan gas generator core for an advanced single-aisle transport. Three different geometry constraints to determine blade heights were used: pure scaling (from larger engine designs), shaft-limited, or shaft-removed. Pure scaling assumed photographic scaling, based on relative engine size, which may underestimate the actual shaft and turbomachinery disk radii which would increase turbomachinery blade hub radius and reduce actual blade heights. Shaft-limited assumes cross-section area reduction based on airflow reduction, but maintains shaft, disk and hub radii set at the minimum for an existing engine of similar thrust class, which results in the greatest reduction of blade height. Shaft-removed assumes the engine could be rearranged such that shafts do not constrain disk or turbomachinery blade design. As defined, shaftremoved gave the most freedom for flow path arrangement to minimize losses, while the shaft-limited was the most constrained and resulted in the highest losses, especially at the lowest corrected flow rates. An example of the losses reported for reducing exit corrected flows from 6 to $1.5 \mathrm{lb}$./s for differing geometry constraints: polytropic efficiency could fall over 5 percentage points for shaft-limited geometry, while efficiency would be reduced only $1 \%$ for the reduction in corrected airflow for the shaft-removed geometry.

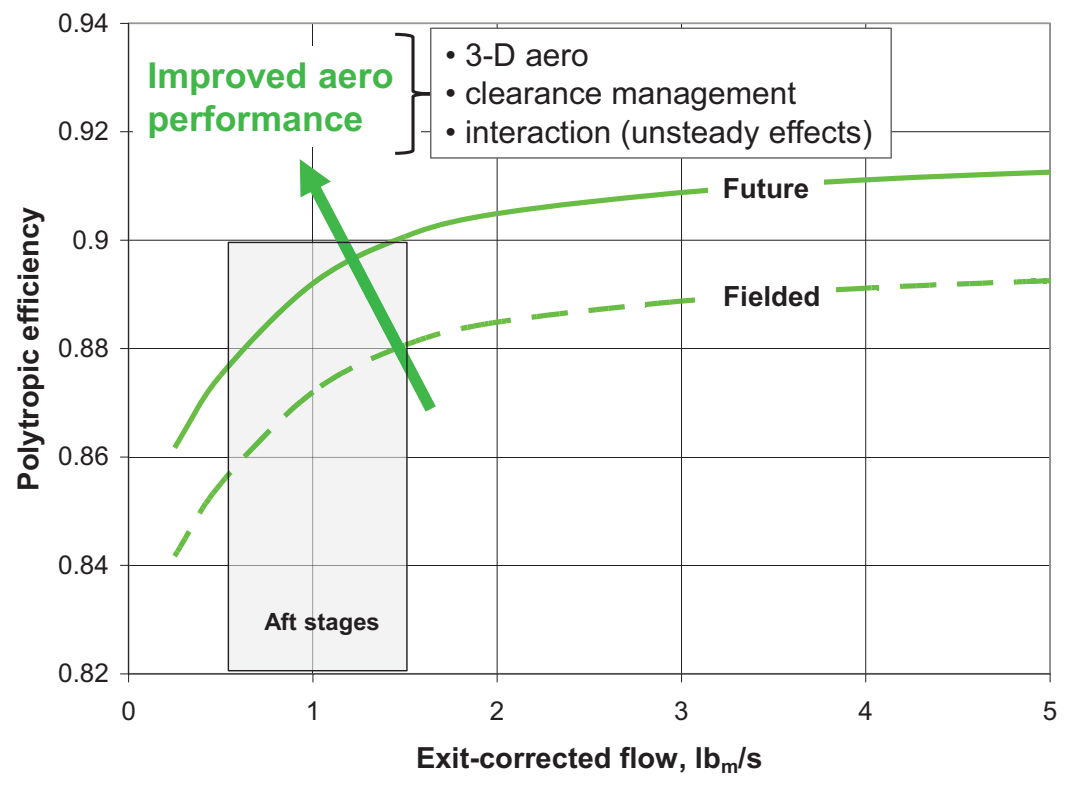

Figure 5. Notional compressor technology polytropic efficiency (from Ref. 6).

\section{Present Engine Design Matrix}

To help quantify the benefits of advanced engine and component technologies on aircraft sizing and fuel burn, four engine concepts representative of different technologies and size were examined; their respective performance to be discussed later. For a current turboshaft engine, power-to-weight and power-specific fuel consumption (PSFC) representative of a CT7-class (1,800 SHP) was assumed. Without a change in engine geometry, a representative model of the GE38 was developed. As modeled, this GE38-class (7,500 SHP) cycle realizes some benefit from larger airflow and technology for some improvement in power-to-weight ratio and PSFC versus the smaller, but similar CT7-class. Two advanced engines were included; the advanced technology generation 1 and 2 turboshaft 
engines. The advanced technology generation 1 engine (formerly referred to as the advanced LCTR2 baseline turboshaft) was developed in previous efforts and incorporates a new engine configuration (for that power class) to take advantage of the advanced technologies considered. For the advanced technology generation 2 engine cycle, the assumptions and methodology used to develop that cycle as well as results will be presented in the Results and Discussion section. For the CT7 and GE38-class cycles, a multi-speed gearbox was assumed to reconcile the power turbine design for fairly constant speed with the required reduction of rotor speed for cruise, which includes a significant $10 \%$ weight penalty to the aircraft drive system during vehicle sizing and mission analysis. For the advanced technology generation 1 and 2 engine cycles, a VSPT was assumed, coupled with a single-speed gearbox, to match power turbine and rotor speeds.

\section{Analysis Methodology}

In order to properly determine the optimum configuration, all subsystem weights and efficiencies must be propagated through the complete aircraft design, typically using a design sizing code. The study reported here utilized the design code NDARC (NASA Design and Analysis of Rotorcraft) ${ }^{24-26}$ v1.5 to study the trades between rotor and engine efficiency as operating speed (rotor tip speed and engine rpm) was varied among the various engines with their respective single or two-speed gearbox. The higher the cruise tip speed, the lighter the gearbox, and the lower the demands upon some engines (reduced range of power turbine rpm variation while maintaining engine operability, power and fuel efficiency) that assumed a fixed-ratio gearbox. These effects are all captured by NDARC, using rotor and engine performance models that incorporate the results of CAMRAD II and NPSS analyses.

Rotor efficiency was determined by Comprehensive Analytical Model of Rotorcraft Aerodynamics and Dynamics (CAMRAD II) ${ }^{27-28}$. Engine performance was estimated with the Numerical Propulsion System Simulation $(\text { NPSS })^{29-30}$. NDARC integrates the rotor and engine performance models with a mission analysis to determine the minimum weight aircraft required to perform the specified mission.

Rotor performance is influenced by wing/rotor interaction, and wing efficiency is strongly affected by the rotor wake ${ }^{2,31-32}$. CAMRAD II was used to analyze all of these effects using a model with multiple wakes, with a wake for each rotor and the wing; performance was calculated for each rotor tip speed. The CAMRAD II results were captured in algebraic rotor and wing performance models for efficient computation within NDARC.

NPSS was used to perform the gas turbine analyses. NPSS contains standard 0/1-D elements for the gas turbine components. These elements are configured into a representative steady-state, thermodynamic model using technology levels for each engine technology assumed. These performance analyses were converted to equivalent, algebraic engine models for NDARC. Engine power-to-weight for present engines was estimated from open sources; for the advance, conceptual engines, methodology and estimated weight are discussed with the particular engine description. $\mathrm{NO}_{\mathrm{x}}$ emission indices were estimated using an empirical correlation representing an advanced, low $\mathrm{NO}_{\mathrm{x}}$ combustor. Further details on this correlation, developed during NASA's Ultra Efficient Engine Technology Program, can be found in Reference 33.

\section{Aircraft and Mission}

Table 1 and Figure 6 summarize the LCTR2 mission requirements and profile. Except for the vertical takeoff and landing portions, the LCTR2 mission is very similar to a regional aircraft mission. To focus results on the effects of engine performance parameters (power-to-weight and PSFC) on design gross weight, empty weight, propulsion system weight, engine size (SHP) and mission fuel burn, all other aircraft technologies and weight scaling relationships were maintained at the same, advanced level as used in previous studies, except for variation in the drive system weight. As mentioned before, for the current cycles, a $10 \%$ weight penalty was included with drive system weight, to account for the additional components and weight for a multi-speed gearbox to match the limited-speed variation power turbine design and operation with varying rotor speed. Reference 11 contains additional

Table 1. LCTR2 mission requirements.

\begin{tabular}{l}
\hline \hline \multicolumn{1}{c}{ Mission summary } \\
\hline Takeoff +2 min hover OGE 5k ISA $+20^{\circ} \mathrm{C}$ \\
Climb at $V_{b r}$ (credit distance to cruise segment) \\
Cruise at $V_{b r}$ for at least $1,000 \mathrm{~nm}$ range, $28 \mathrm{k}$ ISA \\
Descend at $V_{b r}$ (no range credit) \\
1 min hover OGE + landing, 5k ISA $+20^{\circ} \mathrm{C}$ \\
Reserve (diversion): $100 \mathrm{~nm} V_{b r}, 28 \mathrm{k}$ ISA \\
Reserve (emergency): 30 min $V_{b r}, 5 \mathrm{k} \mathrm{ISA}+20^{\circ} \mathrm{C}$ \\
\hline Operational requirements \\
One engine inoperative: Category A at $5 \mathrm{k}$ ISA $+20^{\circ} \mathrm{C}$ \\
All-weather operations: CAT IIIC SNI, Free Flight \\
45-deg banked turn at 80 knots, $5 \mathrm{k}$ ISA $+20^{\circ} \mathrm{C}, 90 \% \mathrm{MCP}$ \\
\hline 7
\end{tabular}

American Institute of Aeronautics and Astronautics 
information concerning how the drive system weight penalty affects vehicle sizing. Other aircraft and mission aspects, such as key constraints and assumptions, LCTR2 design evolution, and performance models used in NDARC are discussed in detail in Reference 12 and will not be repeated here for brevity.

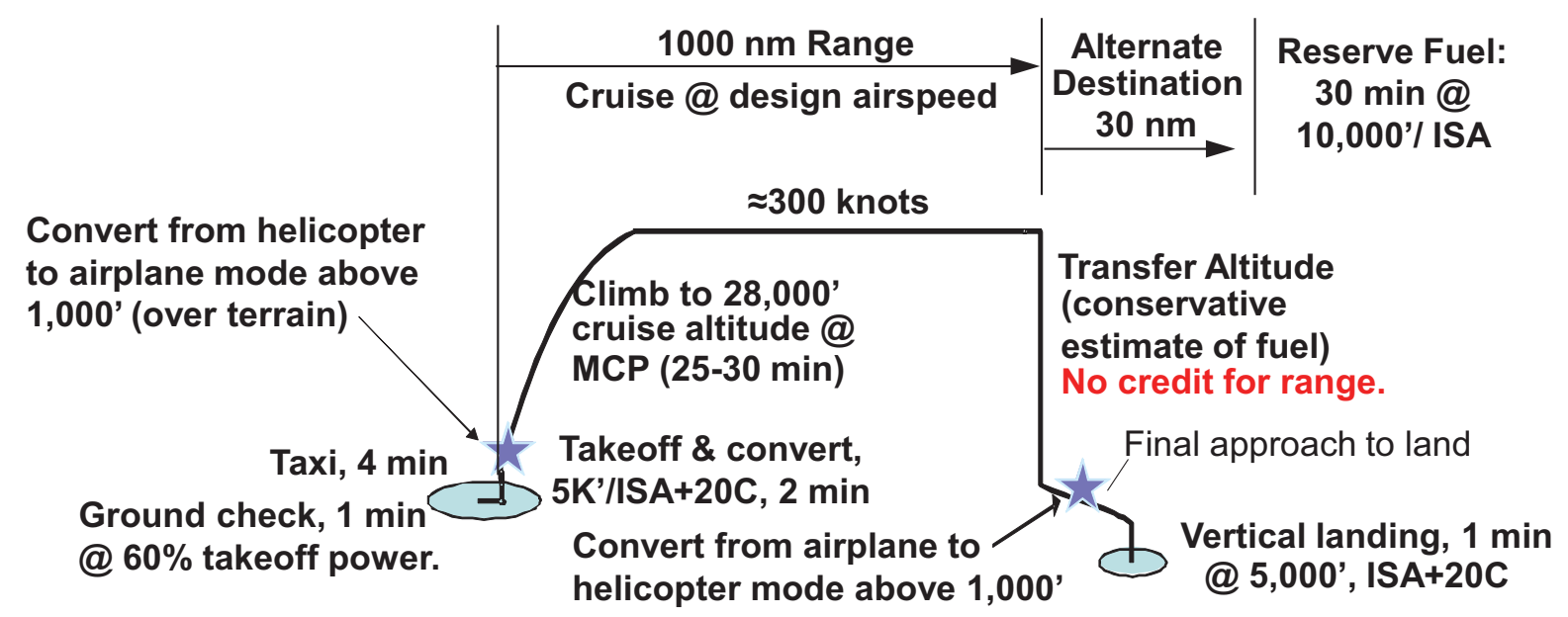

Figure 6. LCTR2 nominal mission profile.

\section{Results and Discussion}

This section starts with the approach to develop the advanced technology generation 2 gas turbine engine, discussing methodology, range and choices for design parameters, and overall engine performance. Then the advanced technology generation 2 engine cycle will be compared with two current-technology engines and the advanced technology generation 1 engine used in previous LCTR2 studies. Next, vehicle sizing and mission performance results assuming various engine technologies, based on these four engines and two additional variations will be presented and discussed. Finally, future research needs are discussed, based on needs identified to realize the advanced technology generation 2 engine cycle.

\section{A. Developing Advanced Technology Generation 2 Engine Performance}

Defining the advanced technology generation 2 engine cycle requires consideration of available component performance, material technologies, and engine configurations. Engine power-to-weight and PSFC were major parameters, but concern about harmful emissions has added $\mathrm{NO}_{\mathrm{x}}$ emitted as a factor to be considered. An exploration of performance across the range of chosen design parameters, similar to that used in Reference 7, was repeated for this effort, although component performance and assumptions were updated to account for advanced technology beyond that used in the advanced technology generation 1 engine. Engine configuration was maintained from Reference 7 as a two-spool, gas generator core engine with a free power turbine on a third shaft (three-spool engine overall); a block representation for the engine modeled in NPSS is shown in Figure 7.

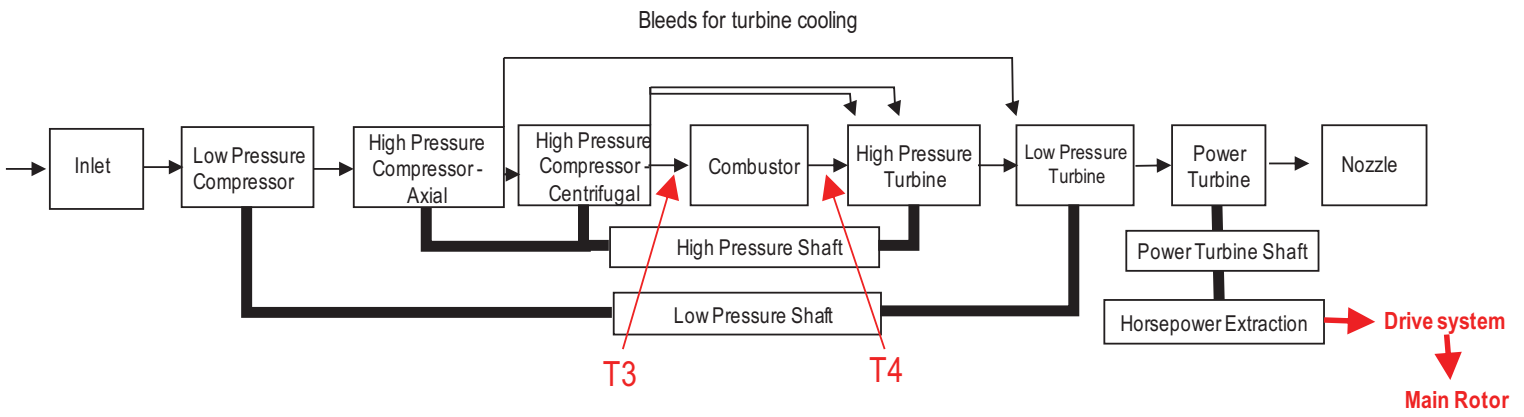

Figure 7. Block representation of NPSS turboshaft gas turbine model. 
For turbomachinery efficiency, an advanced technology generation 2 efficiency trend line was added to Figure 5 and is shown in Figure 8. The advanced technology generation 1 performance level is representative of engines in development and expected to be in production within a decade. The advanced technology generation 2 performance level was set as roughly a $1.5 \%$ efficiency improvement from Generation 1 levels; which seems consistent with previous efficiency gains for a subsequent engine generation. Although recent efforts have suggested much higher efficiency levels are ultimately possible, the chosen level is considered reasonable, obtainable, and will be shown to produce significant benefits for engine performance and the overall vehicle and mission. Also allowing for some performance margins potentially available allows design choices for meeting operational, stability, manufacturing, etc. needs. For the advanced technology generation 1 and 2 engine cycles, compressor polytropic efficiency used the advanced technology generation 1 or 2 efficiency trend lines, respectively, based on exit corrected flow. A similar methodology was used for turbine polytropic efficiency, except it was based on entrance corrected flow. Based on results from Reference 7, the high-pressure centrifugal compressor pressure ratio was set to 2.7. Engine OPR was varied from 20 to 150 . The upper OPR values were allowed to analytically find minimum PSFC values, to help quantify the diminishing reductions in PSFC for high OPR. Parametric exploration of compression work split (ratio of compression work on high-pressure to low-pressure shaft) was performed. Compression work split, together with engine OPR determines the pressure ratios for the low-pressure compressor and high-pressure compressor-axial. Varying compression work split, as noted in Reference 7, results in a very slight $(<0.1 \%)$ benefit in PSFC for increasing work split to the low-pressure spool. From an engine development point-of-view, performing more work on the high-pressure spool, realizes a better engine core for potential derivative engine cycles. Therefore, a 70:30 high-pressure to low-pressure compression work ratio was used for the rest of this effort. Engine airflow was varied to achieve 7,500 SHP (maximum rated power, sea level static, ISA). Combustor exit temperature, (T4) was varied from 2400 to $3200^{\circ} \mathrm{F}$ by $200^{\circ}$ increments. Turbine cooling was still assumed, modeled using the method of Gauntner ${ }^{34}$. The turbine material temperature limit was set to $2700^{\circ} \mathrm{F}$, a value consistent with advanced material concepts in development. This high temperature capability significantly reduced turbine cooling levels and associated penalties compared to previous efforts. To generate a landing / takeoff (LTO) $\mathrm{NO}_{\mathrm{x}}$ value, it was assumed that 1 SHP would produce 1 pound force of thrust. Although this is not entirely accurate, it is an effective way to

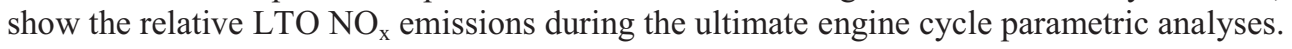

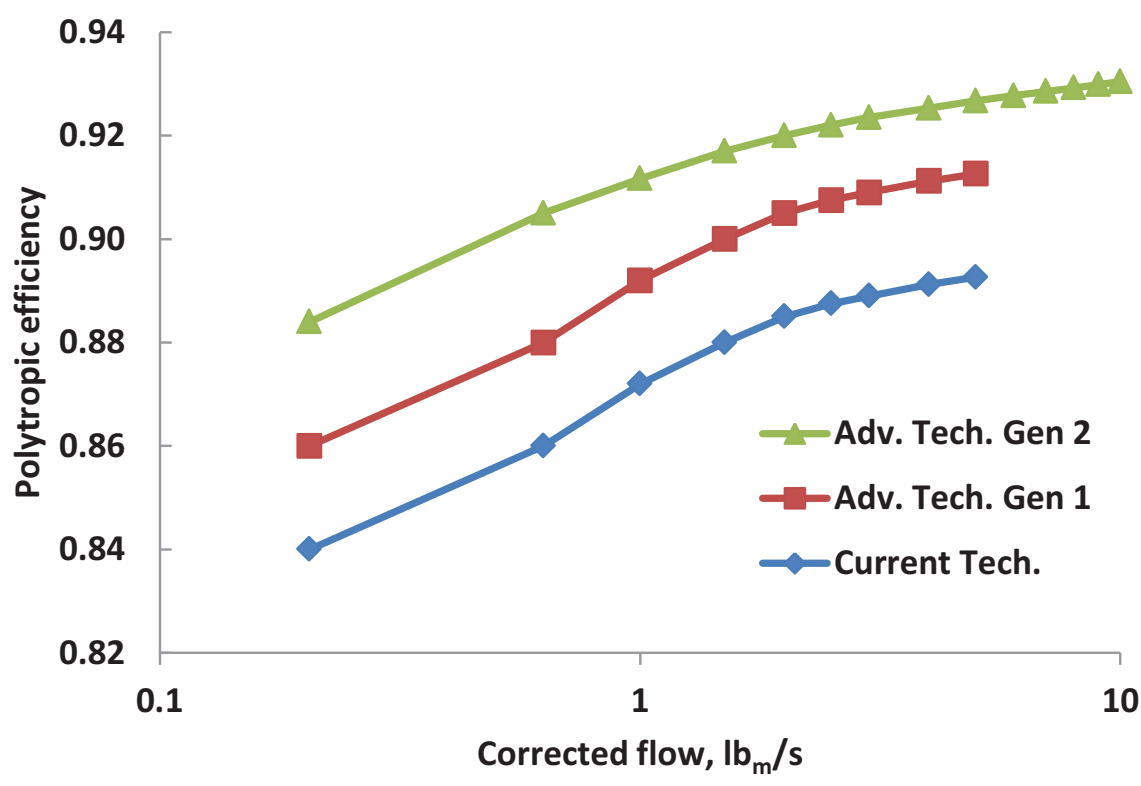

Figure 8. Assumed turbomachinery efficiency characteristics.

\section{B. Advanced Technology Generation 2 Gas Turbine Engine Results}

As seen in Figure 9, PSFC is strongly dependent on OPR and less dependent on T4 for the advanced technology generation 2 engine. Although the minimum PSFC for this given set of assumptions occurs at OPR=130 and $\mathrm{T} 4=3200^{\circ} \mathrm{F}$, many of the other permutations are within $4 \%$ of the minimum PSFC value as engine OPR approaches 
60, which would be an easier compression system and overall engine cycle to develop. At constant OPR, higher T4 values can reduce engine airflow required to achieve a desired SHP significantly, as shown Figure 10. But reduced actual airflow can reduce corrected airflow, which reduces turbomachinery efficiency. This helps explain the limited improvements in PSFC with increased T4. Figure 11 shows that LTO $\mathrm{NO}_{\mathrm{x}}$ emissions are strongly dependent upon OPR and T4, rising quickly as OPRs exceed $60-80$ and $\mathrm{T} 4$ values rise above $2600-2800^{\circ} \mathrm{F}$. The $\mathrm{NO}_{\mathrm{x}}$ results emphasize the importance of considering emissions during engine development and design, and reinforce the importance of combustor research for low $\mathrm{NO}_{\mathrm{x}}$ designs. Considering engine size, complexity, and emissions, there is not an obvious choice for advanced technology generation 2 engine design parameters, but the choice of OPR=60 and T4 $=2800^{\circ} \mathrm{F}$ appears to gain significant benefits in PSFC and airflow/size, without turbomachinery complexity or materials and emissions for pushing to higher OPR or T4.

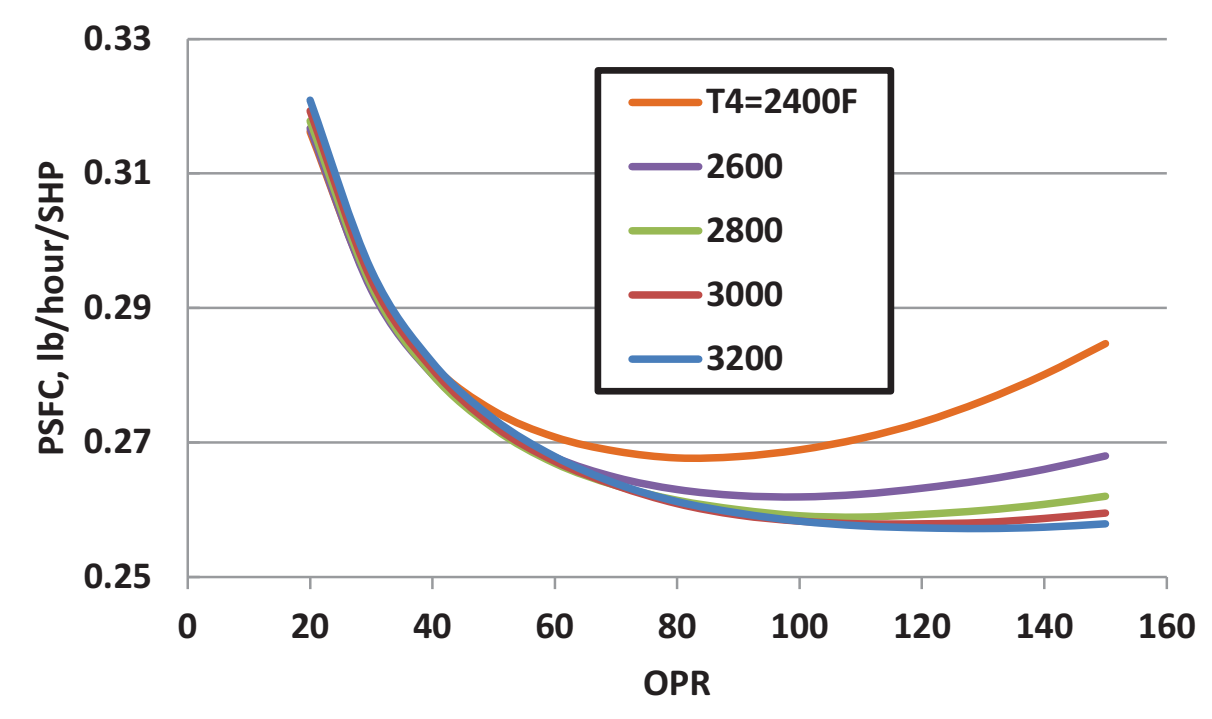

Figure 9. Advanced Technology Generation 2 engine PSFC versus OPR and T4.

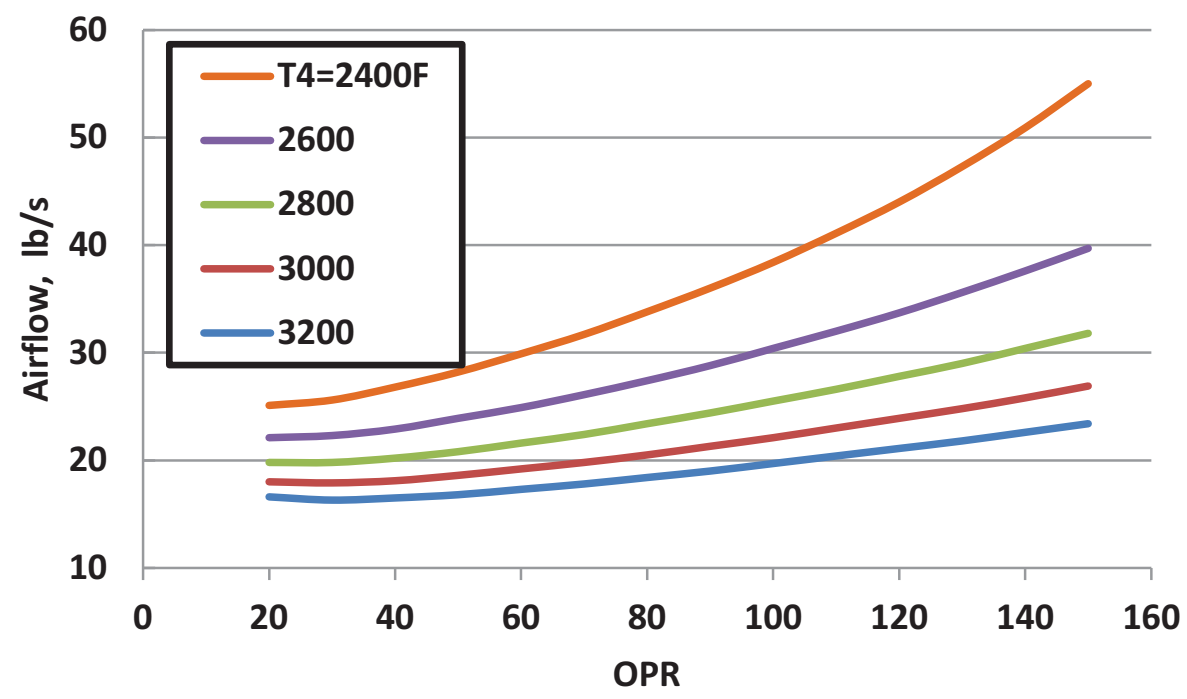

Figure 10. Advanced Technology Generation 2 engine design airflow versus OPR and T4. 


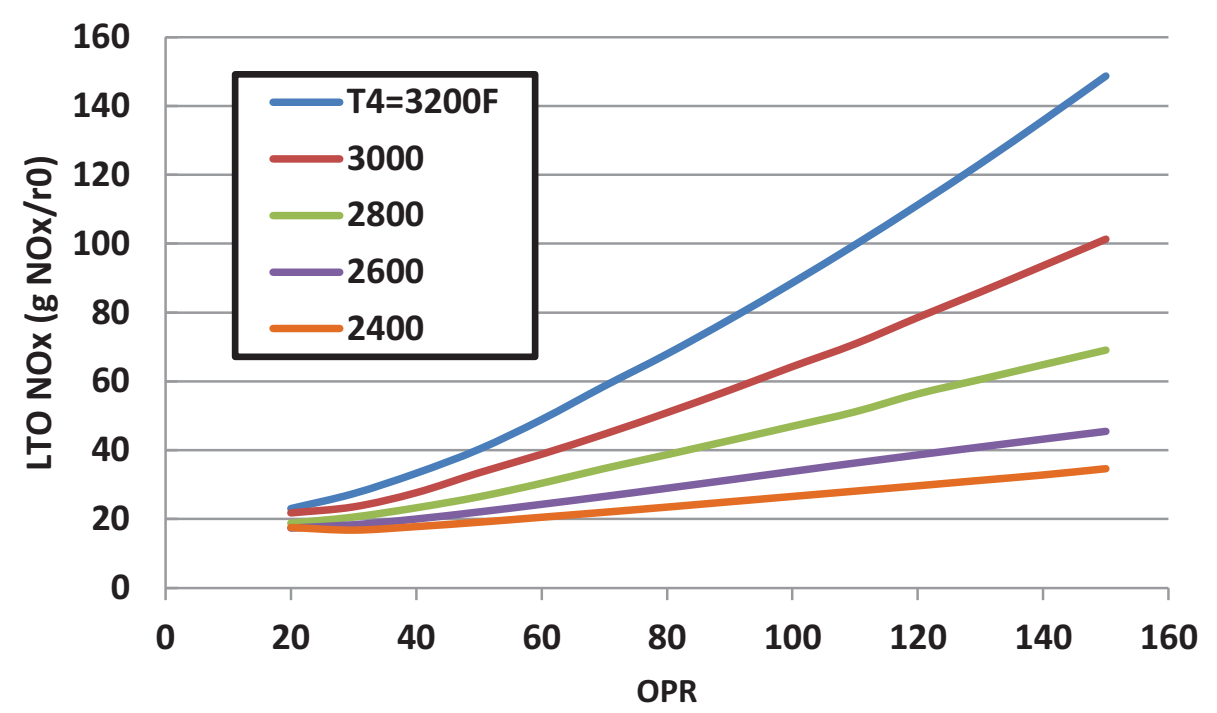

Figure 11. Advanced Technology Generation 2 engine LTO NO versus OPR and T4.

Table 2 lists the four study engines with the original engine parameters used to develop the LCTR and LCTR2 vehicle concepts. For the current technology cycles, engine power-to-weight was pulled from open sources and scaled to represent a 7,500 SHP engine. Engine weight for the advanced technology generation 1 engine was reported in Reference 12 (at a slightly different engine SHP); power-to-weight was maintained to estimate weight for a 7,500 SHP engine. A modest 10\% improvement in power-to-weight was assumed for the advanced technology generation 2 engine. To check vehicle sizing and mission performance sensitivity to advanced technology generation 2 engine performance, two additional cases were analyzed: either a 10\% reduction in PSFC or a $20 \%$ reduction in engine weight. Comparing the various engines, the CT7 is similar in configuration to the GE38 class, but originally designed for lower airflow (SHP), OPR and T4. Scaling CT7 characteristics to 7,500 SHP results in an engine significantly larger and less fuel efficient than the GE38 class engine. Comparing the two ends of the engine technology shown: the advanced technology generation 2 gas turbine engine would weigh almost half $(55 \%)$ as the scaled CT7 class, while using over $40 \%$ less fuel; demonstrating the cumulative benefits of research efforts and application of advanced materials and technologies. A summary of engine design parameters is given in Table 3 . The increase in OPR from the advanced technology generation 1 to 2 engine concepts is obvious from the increase in compression pressure ratios and T3 and is reflected the reduction in compression system exit corrected flow. The assumed improvements in turbomachinery efficiencies mitigated some of the increase in T3 from increased OPR, which has important benefits on engine design and performance.

Table 2. Summary of engine performance parameters.

\begin{tabular}{|l|c|c|c|c|c|c|c|}
\hline \multicolumn{1}{|c|}{ Engine } & $\begin{array}{c}\text { Airflow, } \\
\mathbf{l b}_{\mathbf{m}} \mathbf{s}\end{array}$ & $\mathbf{O P R}$ & $\begin{array}{c}\mathbf{T 4} \text { 4, } \\
{ }^{\mathbf{}} \mathbf{F}\end{array}$ & $\mathbf{P S F C}$ & $\mathbf{W t , ~} \mathbf{l b}$ & $\begin{array}{c}\mathbf{\Delta} \text { PSFC, } \\
\mathbf{\%}\end{array}$ & $\begin{array}{c}\mathbf{\Delta} \mathbf{w t} \\
\mathbf{\%}\end{array}$ \\
\hline LCTR2 (Ref. 2.) & - & - & - & 0.370 & 1000 & base & base \\
\hline Current technology (scaled CT7 class) & 49.2 & 17.7 & 2610 & 0.452 & 1508 & 22.2 & 50.8 \\
\hline Current technology (GE38 class) & 31.0 & 18 & 2800 & 0.385 & 1105 & 4.1 & 10.5 \\
\hline $\begin{array}{l}\text { Advanced Technology Generation 1 } \\
\text { (revised from Ref. 7) }\end{array}$ & 29.4 & 40 & 3000 & 0.312 & 912 & -15.7 & -8.8 \\
\hline $\begin{array}{l}\text { Advanced Technology Generation 2 } \\
(* 10 \% \text { lighter than Generation 1) }\end{array}$ & 20.6 & 60 & 2800 & 0.267 & $* 820$ & -27.8 & -18.0 \\
\hline
\end{tabular}


Table 3. Summary of engine design parameters.

\begin{tabular}{|l|c|c|c|c|c|c|c|}
\hline \multicolumn{1}{|c|}{ Engine } & $\begin{array}{c}\text { Airflow, } \\
\mathbf{l b . / 5}\end{array}$ & $\begin{array}{c}\text { LPC } \\
\mathbf{P R}\end{array}$ & $\begin{array}{c}\text { HPC- } \\
\text { axial } \\
\mathbf{P R}\end{array}$ & $\begin{array}{c}\text { HPC- } \\
\text { centrifugal } \\
\mathbf{P R}\end{array}$ & $\begin{array}{c}\mathbf{T 3 ,} \\
{ }^{\circ} \mathbf{F}\end{array}$ & $\begin{array}{c}\text { HPC exit } \\
\text { corrected } \\
\text { flow, lb./s }\end{array}$ & $\begin{array}{c}\mathbf{T 4 ,} \\
{ }^{\circ} \mathbf{F}\end{array}$ \\
\hline $\begin{array}{l}\text { Advanced Technology Generation 1 } \\
\text { (revised from Ref. 7) }\end{array}$ & 29.4 & 4.93 & 3.01 & 2.70 & 1130 & 0.88 & 3000 \\
\hline Advanced Technology Generation 2 & 21.6 & 6.26 & 3.55 & 2.70 & 1300 & 0.66 & 2800 \\
\hline
\end{tabular}

\section{Vehicle Sizing and Mission Performance Results}

Table 4 provides a summary of important engine and vehicle design values and mission results for the minimum design gross weight cases based on the four engine performance models and two additional advanced technology generation 2 cases described above.

Table 4. Summary of optimum vehicle designs parameters.

\begin{tabular}{|c|c|c|c|c|c|c|c|}
\hline Engine & $\begin{array}{c}\text { Rotor } \\
\text { cruise tip } \\
\text { speed, ft./s }\end{array}$ & $\begin{array}{l}\text { Gross } \\
\text { wt, } l b_{m}\end{array}$ & $\begin{array}{l}\text { Empty } \\
\text { wt, lb } b_{m}\end{array}$ & $\begin{array}{l}\text { Propulsion } \\
\text { wt, } l b_{m}\end{array}$ & $\begin{array}{c}\text { Engine } \\
\text { SHP, } \\
\text { SLS, ISA }\end{array}$ & $\begin{array}{c}\text { Mission } \\
\text { Fuel, } \\
\mathbf{l b}_{\mathrm{m}}\end{array}$ & $\begin{array}{c}\text { Mission } \\
\text { NO }_{\mathrm{x}}, \\
\mathrm{lb}_{\mathrm{m}}\end{array}$ \\
\hline $\begin{array}{l}\text { Current Technology (scaled } \\
\text { CT7 class) }\end{array}$ & 350 & 109,750 & 72,820 & 16,900 & 6,180 & 12,250 & - \\
\hline Current Tech. (GE38 class) & 350 & 98,710 & 64,540 & 13,800 & 5,570 & 10,100 & 22.6 \\
\hline $\begin{array}{l}\text { Advanced Technology } \\
\text { Generation } 1\end{array}$ & 400 & 89,230 & 58,610 & 11,750 & 5,410 & 7,580 & 28.6 \\
\hline $\begin{array}{l}\text { Advanced Technology } \\
\text { Generation } 2\end{array}$ & 425 & 85,870 & 56,950 & 11,350 & 5,460 & 6,330 & 19.2 \\
\hline $\begin{array}{l}\text { Advanced Technology } \\
\text { Generation } 2-10 \% \text { PSFC }\end{array}$ & 425 & 83,980 & 55,940 & 11,050 & 5,350 & 5,590 & 16.9 \\
\hline $\begin{array}{l}\text { Advanced Technology } \\
\text { Generation } 2-20 \% \text { weight }\end{array}$ & 425 & 83,850 & 55,090 & 10,610 & 5,350 & 6,190 & 18.7 \\
\hline
\end{tabular}

Significant weight reductions are realized in design gross weight, empty weight, propulsion and mission fuel burn for each improvement in engine weight and PSFC. These reductions start to diminish as the propulsion and fuel fraction of the overall vehicle design drops from over $25 \%$ of design gross weight to less than $20 \%$, but are still significant. Advanced technology reduces mission fuel burn by an incredible $25 \%$ or more over current technology engines, while the advanced technology generation 2 engine cases realize an additional reduction in fuel use from the generation 1 engine by a still-significant $16-25 \%$. Similar trends for design gross weight and empty weight are shown for the reduction achieved going from current to advanced technology: 10-19\% reductions in design gross and empty weights from current to advanced technology generation 1 and 3-6\% further reductions achieved from applying Generation 1 to Generation 2 technologies. For sensitivity of advanced technology generation 2 engine for reductions in weight or PSFC, $-10 \%$ PSFC and $-20 \%$ weight yielded about the same reductions in design gross weight and engine power; the most significant difference between these two cases was either the reduction in fuel or propulsion weight. This was not surprising as engine weight was almost exactly $1 / 2$ of mission fuel weight for the advanced technology generation 2 engine case.

The original Heavy Lift and LCTR2 studies ${ }^{1,3}$ assumed a constant 7,500 SHP engine size during vehicle sizing and mission analysis. This was a reasonable assumption, engines come in SHP classes and benefits might be shown for a specific SHP that would not exist and 6,000 SHP class engines were insufficient to meet design requirements at that time. This design constraint was later relaxed to determine an optimum engine size as the various engine, vehicle and mission requirements evolved. Except for results from the scaled-up CT7 engine, engine sizes range from 5,300 to 5,600 SHP. Engines in this lower power class would have smaller airflows and potentially lower 
turbomachinery efficiencies and higher PSFC than a 7,500 SHP class engine, but would not be expected to invalidate vehicle designs or mission and sizing trends noted here.

In terms of mission $\mathrm{NO}_{\mathrm{x}}$, going from current to advanced technology generation 1 (and increased engine temperatures from higher OPR and T4) yielded an increase in $\mathrm{NO}_{\mathrm{x}}$ emissions, even with a substantial reduction in fuel use and assumed combustor technology to reduce $\mathrm{NO}_{\mathrm{x}}$. The advanced technology generation 2 engine had an even higher OPR, but with more advanced combustor technology and backing off on design maximum T4 resulted in about a $10 \%$ reduction from current technology and about $1 / 3$ reduction from the amount of $\mathrm{NO}_{\mathrm{x}}$ generated by the advanced technology generation 1 engine case.

Figures 12-16 shows the vehicle sizing and mission analysis trends for design gross and empty weight, propulsion weight (sum of engine and drive system weights), engine maximum rated SHP and mission fuel burn versus rotor cruise tip speed for the cruise condition of 28,000- $\mathrm{ft}$ altitude, 300 knots for the various propulsion systems. Rotor radius follows design gross weight trends and therefore is not shown. Most trends shown in Figures 12-16 are nearly flat around their optimum designs. Optimum rotor cruise tip optimized to slighter lower value for current technology engine cases that assumed a multi-speed gearbox (tip speed of $350 \mathrm{ft}$./s) than for the advanced technology generation engine cases that assumed a single-speed gearbox / VSPT (tip speed range of 400-425 ft./s). For the multi-speed gearbox designs, this illustrates the tradeoff of improved rotor cruise efficiency with reduced tip speed versus gearbox weight (increased gearbox weight as cruise tip speed is reduced resulting from higher torques and the larger gear ratio / speed reduction between engine power turbine and rotor rpms). For the advanced and ultimate engines using VSPT technology and single-speed gearboxes, the tradeoff is more strongly on rotor versus engine VSPT cruise efficiencies. Rotor efficiency increases at cruise for reduced tip speed (rpm), while VSPT efficiency drops. This repeats study results explored and discussed in greater detail in References 11 and 12. In those efforts, for a given technology level, the minimum TOGW between the VSPT with single-speed gearbox versus more traditional power turbine designs with multi-speed gearbox were very similar, where the former generally resulted in slightly lighter propulsion and drive system weight and the latter slightly less mission fuel. As mentioned before, these results are strongly dependent on the technology assumptions for efficiency and weight for the VSPT and gearbox systems.

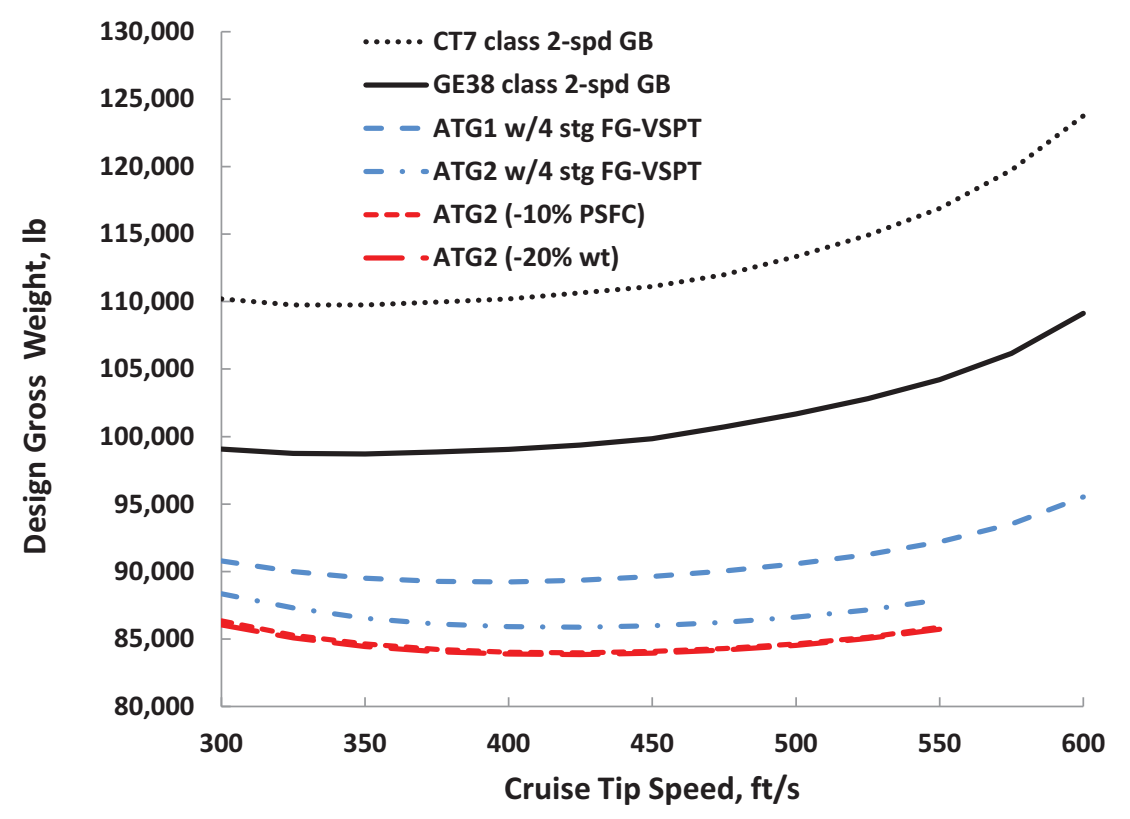

Figure 12. Design Gross Weight versus rotor cruise tip speed. 


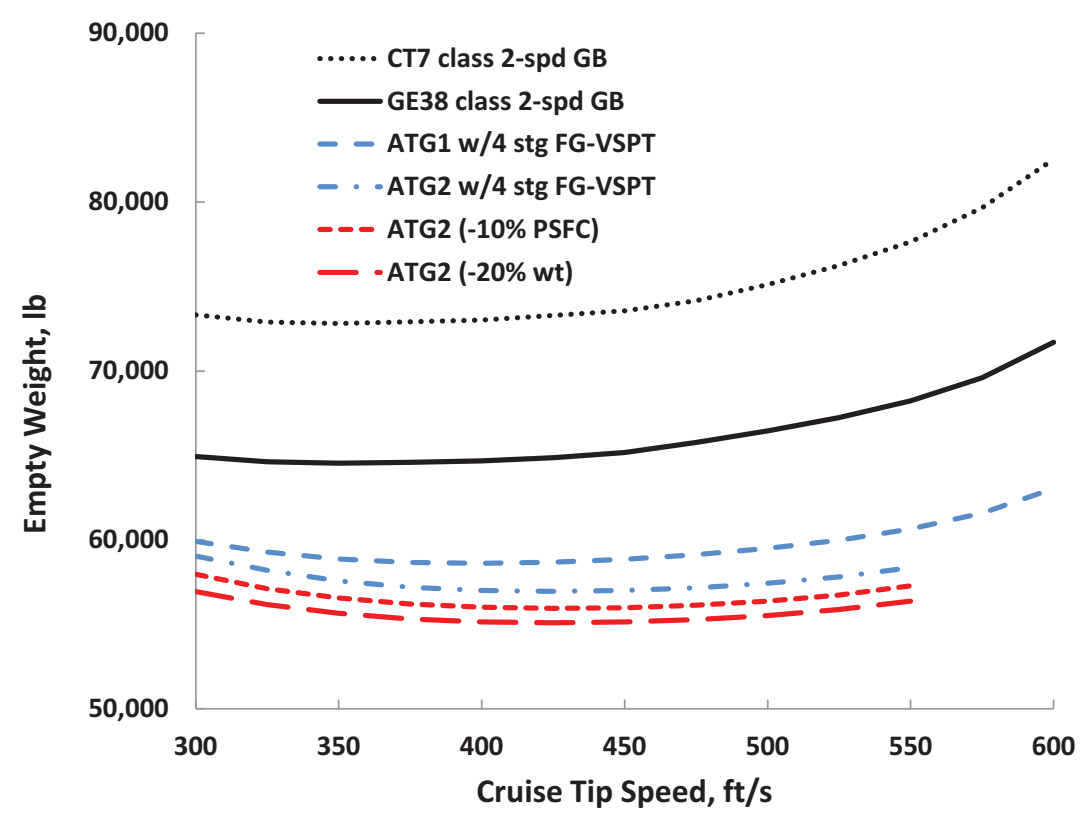

Figure 13. Empty Weight versus rotor cruise tip speed.

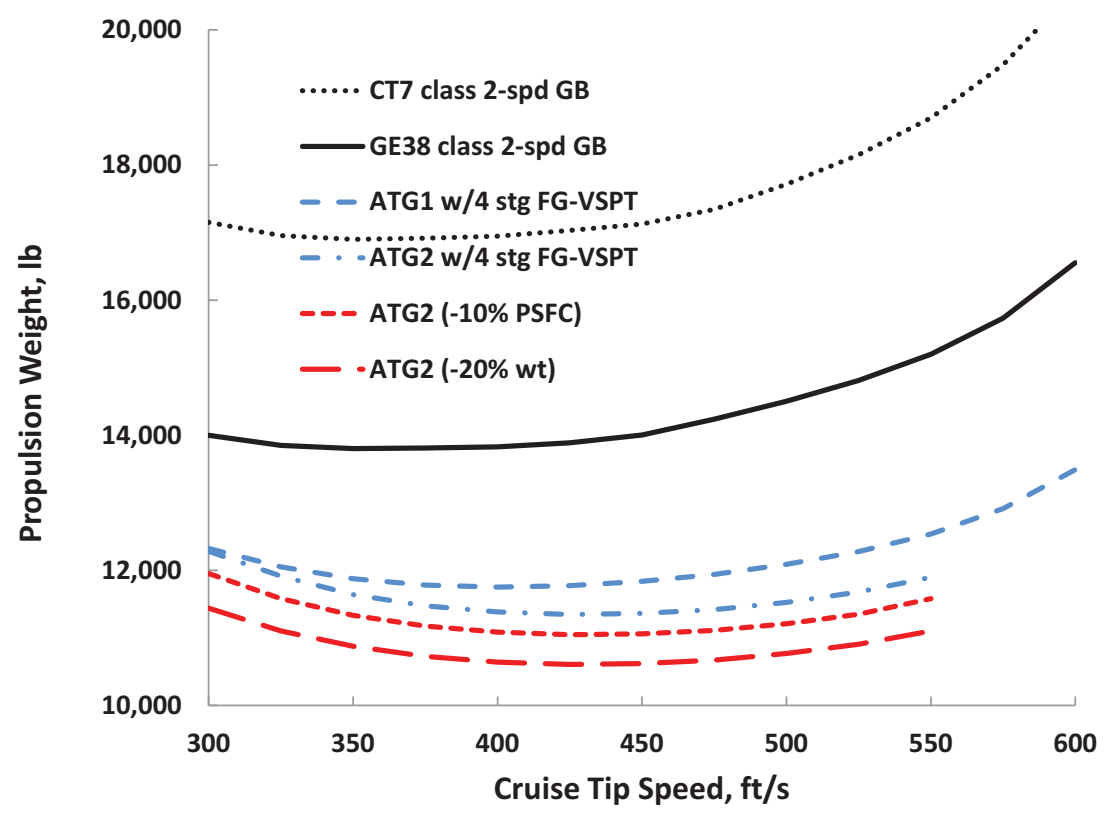

Figure 14. Propulsion Weight versus rotor cruise tip speed. 


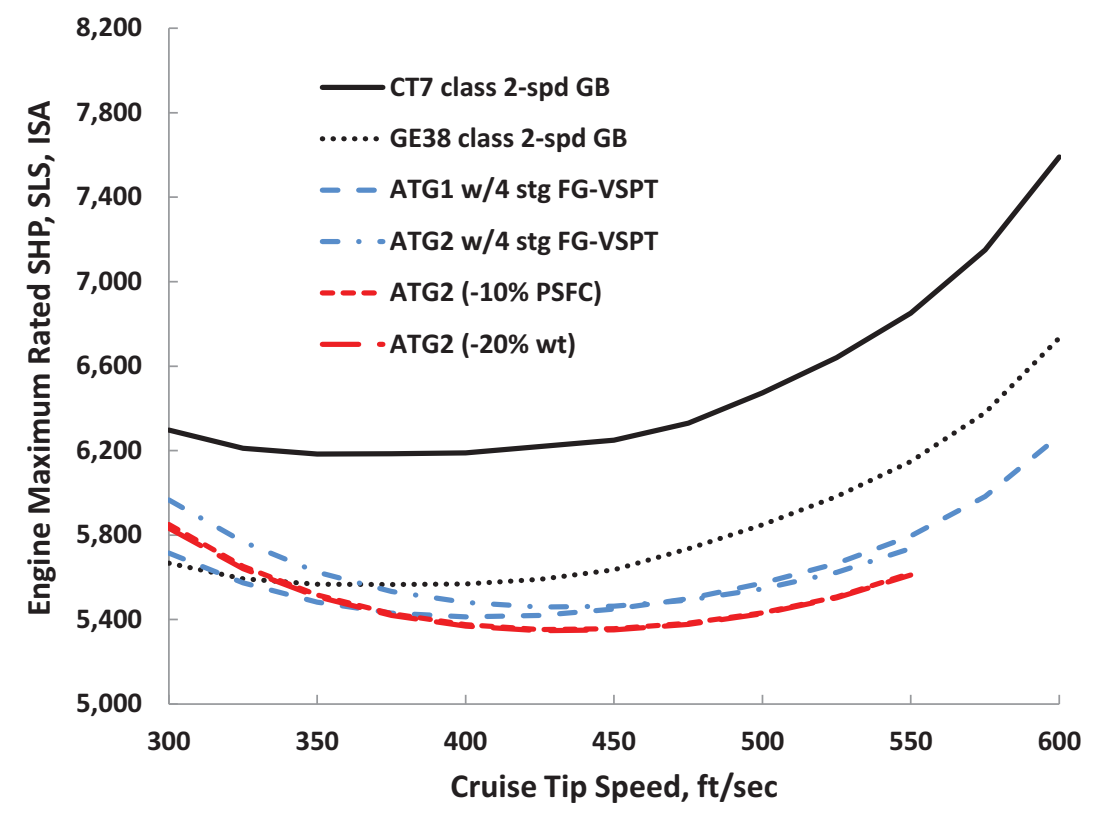

Figure 15. Engine Maximum rated SHP versus rotor cruise tip speed.

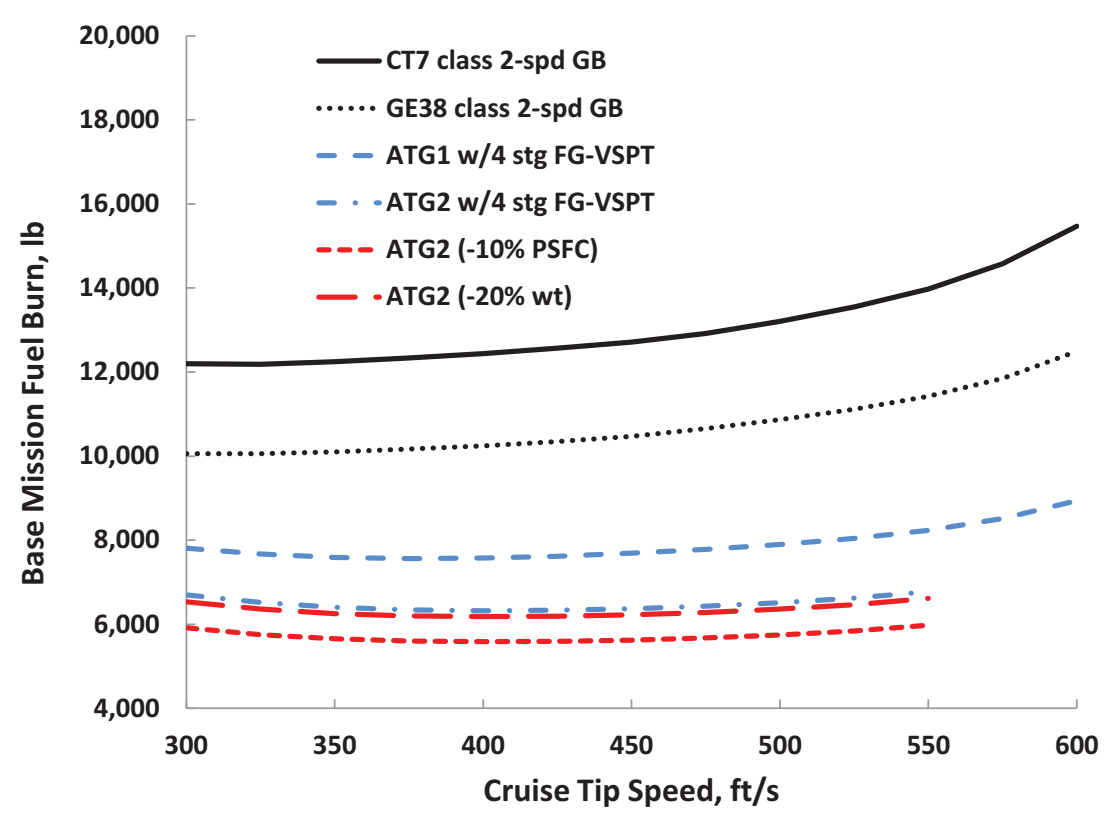

Figure 16. Mission Fuel Burn versus rotor cruise tip speed.

\section{Future research needs}

Significant benefits have been identified for engine weight, fuel and reduction of harmful emissions through the use of advanced technologies. Based on recent efforts to quantify maximum potential and reasonable future turbomachinery efficiencies and include material advances (such as higher temperature capability, increased strength 
and reduced weight), there are still significant improvements that can be realized. As suggested in Reference 8 and worth repeating here, the benefits have been achieved by a combination of technologies, judiciously applied over an entire engine cycle design. Three technology areas noted include turbomachinery, combustor, and material / manufacturing; although these areas will be discussed separately, they are definitely interrelated.

Various turbomachinery efforts have identified the major losses that occur, especially in the high-pressure portions of a gas turbine engine. The aft stages of the compression system as well as the first, high pressure turbine stages are a challenging design, manufacturing and operational environment. Higher pressures increase the driving forces for many losses and turbomachinery design challenges. At such small sizes (very small turbomachinery blade heights), there are theoretical flow path and more specifically blade designs options that can minimize aerodynamic losses inherent from low Reynolds number, high relative surface roughness, high clearance to span ratios, shroud losses, blade leading and trailing edge effects, etc. During the engine design and development process, some turbomachinery efficiency is often sacrificed to add operational stability and margin. Improved understanding on operational requirements and mitigating sources of instability can reduce the amount of efficiency traded for operational requirements. An additional challenge for research and understanding is whether the design is axial, centrifugal / radial or a combination of both. Each has strengths and weaknesses, depending on the application and requirements.

Combustor technology continues to gain importance with increased environmental concerns to reduce harmful emissions, even as combustor conditions move in the direction that enhances their generation. $\mathrm{NO}_{\mathrm{x}}$ requirements continue to get more stringent and applied to more engine classes. Another challenge is new fuel blends or synthetics that are becoming more available or possible. These new fuels have different chemical properties and change the combustor kinetics. Combustor interaction with the turbomachinery around it must also be considered. Combustor pressure oscillation and uneven heat release / exit temperature patterns can have adverse effects on the stability and efficiency of the surrounding turbomachinery and overall engine performance and operation. An improved understanding of the complex aerodynamic, thermodynamic and chemical kinetic combustor environment is needed to meet stricter combustor and overall engine design requirements.

Finally, material technologies are needed that improve strength, weight and temperature capabilities. Improved strength could enable turbomachinery designs, such as reduced blade thicknesses for reduced losses and improved efficiency, flow stability, etc. Reduced overall and component weights are always important to aircraft design. Improved, higher temperature capabilities can reduce losses and complexity from engine cooling and secondary flows. This is coupled with manufacturing technologies / capabilities to meet differing requirements (efficiency, manufacturability, durability, life, cost, etc.). The engine operational environment varies across a wide range of temperatures, pressures, moisture levels, ice and other particles, etc.; this drives material requirements and solutions that span all aspects of material use today and in the future.

\section{Conclusion}

The Large Civil Tiltrotor (LCTR2) conceptual design was used to explore the benefits of engine technology on vehicle sizing and mission analysis. Previous efforts to refine the LCTR2 conceptual design, specific engine operational and performance characteristics, and engine specific component technologies were reviewed and discussed. An engine design methodology and component technology performance levels (consistent with previous efforts and revised with more recent findings) were used to define achievable, advanced technology generation 2 gas turbine component performance. Parametric analysis to define performance for the advanced technology generation 2 engine was performed and compared with performance for current and advanced technology generation 1 gas turbine engines. These four engine concepts plus two variations on the advanced technology generation 2 engine were used for vehicle sizing and mission analysis based on the LCTR2 vehicle and reference mission. Results were presented and discussed, as well as technology efforts necessary to realize the advanced technology generation 2 gas turbine component performance proposed.

The advanced technology engine cycle resulted in mission fuel burn reductions of $25 \%$ or more from current technology engine cycles, with an additional reduction of $16-25 \%$ from application of advanced technology generation 2 levels. Vehicle design gross weight and empty weight reductions diminished with advancing technology level as the propulsion and fuel fractions became less significant portions of the overall design, but still resulted in 10-19\% reductions as technology advanced from current to advanced technology generation 1, and 3-6\% from advanced technology generation 1 to 2 . Amount of mission $\mathrm{NO}_{\mathrm{x}}$ rose with the high combustor exit temperature (T4) assumed for the advanced engine cycle, but was reduced by $1 / 3$ for the advanced technology generation 2 engine cycle through a combination of combustor technologies, reduced fuel use, and reduced T4. The original Heavy Lift and LCTR2 vehicle studies assume 7,500 SHP engines would be required to meet vehicle and mission 
requirements, while subsequent studies (including this one) suggest 6,000 SHP class engines would have sufficient power. However, it is harder to achieve stringent weight, fuel efficiency and emissions requirements with smaller engines.

This study re-emphasizes the particular turbomachinery technology needs that have been highlighted before, especially the need for performance, efficiency and operability for small flow path and blade sizes. However, to meet overall engine, vehicle and mission performance goals, turbomachinery advances must be coupled with combustor and a range of material technologies for an overall solution to ever more stringent and broader requirements.

\section{Acknowledgments}

The author would like to thank the management of the Rotary Wing vehicle project within the NASA Fundamental Aeronautics Program for supporting this research.

\section{References}

${ }^{1}$ Johnson, W.; Yamauchi, G. K.; and Watts, M. E., "NASA Heavy Lift Rotorcraft Systems Investigation,” NASA TP-2005213467, September 2005.

${ }^{2}$ Acree, C. W., "Integration of Aeromechanics Analysis with the Conceptual Design of a Large Civil Tiltrotor," AHS Aeromechanics Specialists' Conference, San Francisco, CA, January 2010.

${ }^{3}$ Acree, C. W., Yeo, H., and Sinsay, J. D., "Performance Optimization of the NASA Large Civil Tiltrotor," International Powered Lift Conference, London, UK, July 2008, NASA TM-2008-215359, June 2008.

${ }^{4}$ Acree, C. W., "Aerodynamic Limits on Large Civil Tiltrotor Sizing and Efficiency," AHS Aeromechanics Specialists' Conference, San Francisco, CA, January 2014.

${ }^{5}$ Robuck, M., Wilkerson, J. B., Maciolek, R., Vonderwell, D., “The Effect of Rotor Cruise Tip Speed, Engine Technology and Engine/Drive System RPM on the NASA Large Civil Tiltrotor (LCTR2) Size and Performance,” NASA/CR-2013-216593, March 2013.

${ }^{6}$ Welch, G. E., Hathaway, M. D., Skoch, G. J., and Snyder, C. A., "Rotary-Wing Relevant Compressor Aero Research and Technology Development Activities at Glenn Research Center," AHS International, 65th Annual Forum \& Technology Display, Grapevine, Texas, May 2009, NASA TM-2012-217280 and ARL-TR-4757, March 2012.

${ }^{7}$ Snyder, C. A., and Thurman, D. R., "Gas turbine characteristics for a Large Civil Tilt-Rotor (LCTR)," AHS International, 65th Annual Forum \& Technology Display, Grapevine, Texas, May 27-29, 2009, NASA/TM-2010- 216089.

${ }^{8}$ Snyder, C. A. and Thurman, D. R., "Effects of Gas Turbine Component Performance on Engine and Rotary Wing Vehicle Size and Performance," AHS 66th Annual Forum Proceedings, Phoenix, AZ, May 2010.

${ }^{9}$ Snyder, C. A., "Defining Gas Turbine Engine Performance Requirements for the Large Civil Tiltrotor (LCTR2)," AHS 67th Annual Forum Proceedings, Virginia Beach, VA, May 2011.

${ }^{10}$ Robuck, M., Wilkerson, J. B., Snyder, C. A., Zhang, Y., Maciolek, B., "Study and Sub-System Optimization of Propulsion and Drive Systems for the Large Civil TiltRotor (LCTR2) Rotorcraft," AHS 69th Annual Forum, Phoenix, Arizona, May 2013, also NASA TM-2013-218103, December 2013.

${ }^{11}$ Acree, C. W. and Snyder, C. A., "Influence of Alternative Engine Concepts on LCTR2 Sizing and Mission Profile," AHS Future Vertical Lift Aircraft Design Conference, San Francisco, CA, January 2012.

${ }^{12}$ Snyder, C. A., and Acree, C. W., "Preliminary Assessment of Variable Speed Power Turbine Technology on Civil Tiltrotor Size and Performance," AHS 68th Annual Forum, Fort Worth, TX, May 2012.

${ }^{13}$ Litt, J. S., Edwards, J. M., DeCastro, J. A., “A Sequential Shifting Algorithm for Variable Rotor Speed Control,” AHS 63rd Annual Forum Proceedings, Virginia Beach, VA, May 2007, NASA TM-2007-214842 and ARL-TR-4086, June 2007.

${ }^{14}$ Stevens, M. A., Handschuh, R. F., and Lewicki, D. G., "Variable/Multispeed Rotorcraft Drive System Concepts," NASA TM-2009-215456 and ARL-TR-4758, March 2009.

${ }^{15}$ Stevens, M. A., Handschuh, R. F., and Lewicki, D. G., "Concepts for Variable/Multi-Speed Rotorcraft Drive System,” AHS International 64th Annual Forum and Technology Display, Montreal, Canada, April 29-May 1, 2008, NASA TM-2008-215276 and ARL-TR-4564.

${ }^{16}$ D'Angelo, M., "Wide Speed Range Turboshaft Study,” NASA/CR-1995-198380, Aug, 1995.

${ }^{17}$ Welch, G. E., McVetta, A. B, Stevens, M. A., Howard, S. A.; Giel, P. W.; Ameri, A. A., To, W., Skoch, G. J.; Thurman, D. R., "Variable-Speed Power-Turbine Research at Glenn Research Center," AHS International, 68th Annual Forum and Technology Display, Fort Worth, Texas, May 2012, NASA TM-2012-217605, July 2012.

${ }^{18}$ Niedzwiecki, R. W., "Small engine technology programs," AIAA Aeropropulsion 1987, Accession Number: 92 N22532.

${ }^{19}$ Niedzwiecki, R. W., Meitner, P. L., "Small gas turbine engine technology," NASA/Army Rotorcraft Technology. Volume 2: Materials and Structures, Propulsion and Drive Systems, Flight Dynamics and Control, and Acoustics. NASA-CP-2495-VOL2, NAS 1.55:2495-VOL-2, Conference at Moffett Field, CA, 17-19 March 1987. 
${ }^{20}$ Vanco, M. R., Wintucky, W. T., Niedzwiecki, R. W., “An Overview of the Small Engine Component Technology (SECT) Studies," AIAA-86-1542, AIAA/ASME/SAE/ASEE 22nd Joint Propulsion Conference, Huntsville, AL, June 1986, , also NASA TM-88796 and USAAVSCOM TR 86-C-23.

${ }^{21}$ Meredith, F. W: "Cooling of Aircraft Engines. With Special Reference To Ethylene Glycol Radiators Enclosed In Ducts," Aeronautical Research Council R\&M 1683, 1936.

${ }^{22}$ Hall, D. K., "Performance Limits of Axial Turbomachinery Stages," Master's Thesis, Massachusetts Institute of Technology, December 2010.

${ }^{23}$ DiOrio, A. G., "Small Core Axial Compressors for High Efficiency Jet Aircraft," Master's Thesis, Massachusetts Institute of Technology, September 2012.

${ }^{24}$ Johnson, W., "NDARC, NASA Design and Analysis of Rotorcraft," NASA TP 2009-215402, December 2009.

${ }^{25}$ Johnson, W., "NDARC-NASA Design and Analysis of Rotorcraft: Theoretical Basis and Architecture," AHS Aeromechanics Specialists' Conference, San Francisco, CA, January 2010.

${ }^{26}$ Johnson, W., "NDARC-NASA Design and Analysis of Rotorcraft: Validation and Demonstration." AHS Aeromechanics Specialists' Conference, San Francisco, CA, January 2010.

${ }^{27}$ Johnson, W., "Rotorcraft Aerodynamics Models for a Comprehensive Analysis," AHS 54th Annual Forum Proceedings, Washington, D.C., 1998.

${ }^{28}$ Johnson, W., "CAMRAD II Comprehensive Analytical Model of Rotorcraft Aerodynamics and Dynamics," Johnson Aeronautics, Palo Alto, CA, 2005.

${ }^{29}$ Claus, R. W., Evans, A. L., Lytle, J. K., Nichols, L. D. "Numerical Propulsion System Simulation,” Computing Systems in Engineering, vol. 2, no. 4, 1991, pp. 357-364.

${ }^{30}$ Jones, Scott M., "An Introduction to Thermodynamic Performance Analysis of Aircraft Gas Turbine Engine Cycles Using the Numerical Propulsion System Simulation Code," NASA/TM-2007-214690.

${ }^{31}$ Kroo, I., "Propeller-Wing Integration for Minimum Induced Loss," Journal of Aircraft, Vol. 23, No. 7, July 1986.

${ }^{32}$ McVeigh, M. A., Grauer, W. K., and Paisley, D. J., "Rotor/Airframe Interactions on Tiltrotor Aircraft," AHS 44th Annual Forum Proceedings, Washington, D.C., June 1988.

${ }^{33}$ Guynn, M.D., Berton, J.J., Fisher, K.L., Haller, W.J., Tong, M., Thurman, D.R., "Engine Concept Study for an Advanced Single-Aisle Transport,” NASA TM-2009-215784, August 2009.

${ }^{34}$ Gauntner, J. W., "Algorithm for Calculating Turbine Cooling Flow and the Resulting Decrease in Turbine Efficiency," NASA TM 81453, 1980. 